\title{
Factors contributing improvement of syringomyelia and surgical outcome in type I Chiari malformation
}

Young Seok Park • Dong-Seok Kim • Kyu-Won Shim • Jung-Hee Kim • Joong-Uhn Choi

Published online: 6 March 2009

(C) Springer-Verlag 2009

\section{Erratum to: Childs Nerv Syst \\ DOI 10.1007/s00381-008-0763-9}

Unfortunately, we had indicated the affiliations of the authors incorrectly in the article. The correct affiliations are given below.

The online version of the original article can be found at http://dx.doi. org/10.1007/s00381-008-0763-9.

Y. S. Park $\cdot$ D.-S. Kim $(\bowtie) \cdot$ K.-W. Shim

Department of Pediatric Neurosurgery, Brain Research Institute,

College of Medicine, Yonsei University,

Seoul, South Korea

e-mail: dskim33@yuhs.ac

J.-H. Kim

Department of Neurosurgery, Seoul Medical Center,

Seoul, South Korea

J.-U. Choi

Departement of Neurosurgery, Bundang CHA Hospital,

College of Medicine, Pochon CHA University,

Seongnam, South Korea 